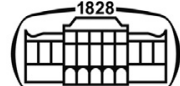

AKADÉMIAI KIADÓ

Acta Veterinaria

Hungarica

$68(2020) 1,91-94$

DOl:

$10.1556 / 004.2020 .00017$

(c) 2020 Akadémiai Kiadó, Budapest

\section{ORIGINAL ARTICLE}

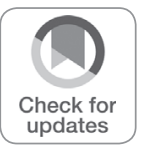

${ }^{*}$ Corresponding author.

Tel.: +39 (02) 50334174

E-mail: monicaprobo@gmail.com

\title{
Prevalence, survival and subsequent fertility of dairy and beef cows with uterine prolapse
}

\author{
AUGUSTO CARLUCCIO $^{1}$, IPPOLITO DE AMICIS $^{1}$, \\ MONICA PROBO $^{2 *}$ (D), BRUNELLA GIANGASPERO ${ }^{1}$ and \\ MARIA CRISTINA VERONESI ${ }^{2}$
}

\author{
${ }^{1}$ Facoltà di Medicina Veterinaria, Università degli Studi di Teramo, Località Piano D’Accio, 64100, \\ Teramo, Italy \\ ${ }^{2}$ Dipartimento di Medicina Veterinaria, Università degli Studi di Milano, Via Celoria 10, 20133, \\ Milan, Italy
}

Received: September 19, 2019 • Accepted: January 11, 2020

Published online: May 8, 2020

\begin{abstract}
The aim of this study was to evaluate the prevalence of uterine prolapse in cows and assess its effects on survival and subsequent fertility. Of 33,450 calving cows considered retrospectively, $216(0.6 \%)$ developed uterine prolapse. A higher prevalence was found in beef cows ( $\mathrm{n}=57 / 5,700$ cows, $1 \%$ ) compared to dairy cows $(\mathrm{n}=157 / 27,750$ cows, $0.6 \%)$. Treatment consisted of cleaning and replacing the uterus with local administration of antibiotics, and applying a harness for uterine containment. The recovery rate was $81.9 \%(n=177)$, similar in dairy $(n=129 ; 81.1 \%)$ and beef $(n=48 ; 84.2 \%)$ cows. Of the 216 cows with uterine prolapse, 18 (8.3\%) died before or immediately after treatment; 21 cows (9.7\%) were voluntarily culled for economic reasons (low milk yield, low fertility, insufficient weight gain). All recovered dairy cows were artificially inseminated with semen of proven fertility after a voluntary waiting period of 50 days; the beef cows were naturally mated. Among the 172 inseminated/mated cows, $84.7 \%(\mathrm{n}=150)$ became pregnant $(83.7 \%$ dairy cows, $87.5 \%$ beef cows $)$, while $15.2 \%(\mathrm{n}=27)$ did not conceive. Recurrence of uterine prolapse at subsequent calvings was recorded in one dairy cow. Based upon the data presented here, treated cows with uterine prolapse showed high chances of survival and conception, and a low risk of recurrence.
\end{abstract}

\section{KEYWORDS}

uterine prolapse, cattle, prevalence, survival, fertility

\section{INTRODUCTION}

Uterine prolapse has been recorded in all animal species, but it is most common in the cow, shortly after parturition (Roberts, 1986). Higher incidence is registered in dairy than in beef cows, and in multiparous compared to primiparous cows (Vandeplassche et al., 1963; Noakes et al., 2001). The literature emphasises the fact that the prevalence of uterine prolapse is highly variable but generally low within the bovine population, ranging between $0.2 \%$ (Odegaard, 1977) and 0.3-0.5\% (Vandeplassche et al., 1963; Patterson et al., 1981; Noakes, 1986; Richter and Goetze, 1986). In the majority of cases, the prolapse occurs within a few hours of an otherwise normal second-stage labour, although in some cases it may be delayed by several days (Noakes et al., 2001).

Various predisposing factors have been suggested for uterine prolapse in the cow, i.e. the presence of uterine atony due to hypocalcaemia or prolonged dystocia, fetal oversize, fetal traction, retained fetal membranes, chronic vaginal prolapse, paresis, delayed cervical closure and, finally, an excessive laxity of the perineal tissues (Risco et al., 1984; Potter, 2008). The triggering factors include, however, the tensile forces exerted for the extraction of the fetus, and the intraabdominal pressure forces exerted on the uterus by the action of the abdominal press. 
Uterine prolapse is regarded as an emergency condition, and it should be managed before excessive oedema, mucosal trauma, contamination, and fatal haemorrhage could lead to a poor prognosis (Miesner and Anderson, 2008). It is no coincidence that some authors (Odegaard, 1977; Patterson et al., 1981; Jubb et al., 1990) regard uterine prolapse as one of the most frequent causes of mortality in bovine obstetric practice, reaching mortality rates above $25 \%$. In one study, a two-week survival rate of $72.4 \%$ (Gardner et al., 1990) was found, with other studies reporting survival rates of $73.5 \%$ (Jubb et al., 1990) and 80\% (Murphy and Dobson, 2002). Cows that had delivered a live calf showed a better survival rate; the absence of severe hypocalcaemia was also found to be a favourable prognostic indicator (Potter, 2008). Treatment usually consists of replacing the everted uterus; following replacement, temporary closure of the vulva with a Buhner's suture can be performed, but this latter procedure is deemed unnecessary by many authors (Potter, 2008). Occasionally, when extensive calving or environmental trauma has occurred, uterine amputation to salvage the cow for slaughter is required (Miesner and Anderson, 2008).

Along with the favourable prognosis, it is also important to consider the long-term effects on fertility. When it becomes complicated after inadequate treatment, uterine prolapse can cause a significant fertility reduction in cattle (Patterson et al., 1981). However, because of the low occurrence, only a limited number of comprehensive studies have studied the fertility of cows affected by uterine prolapse. Moreover, data reported in the literature are conflicting: Patterson et al. (1981) obtained only $28 \%$ of pregnancies in primiparous cows and $57.9 \%$ in multiparous ones, while Jubb et al. (1990) reported satisfactory results with $69 \%$ of pregnancies; Odegaard (1977) reported infertility in $18.7 \%$ of cows affected by uterine prolapse, while Noakes (1986) in only $10 \%$.

The aim of the present retrospective study was to expand field studies on the prevalence of uterine prolapse in dairy and beef cows, and to evaluate the success of intervention in terms of cow survival and subsequent fertility.

\section{MATERIALS AND METHODS}

The present study was carried out during a 10 -year period in dairy and beef herds in the southern and central part of Italy. The dairy cattle population studied $(\mathrm{n}=27,750)$ included cows of the Italian Friesian, Italian Brown, Jersey and Pezzata Rossa breeds. Cows were housed in free stall barns and divided into the following groups: lactation cows, dry cows and pregnant heifers, and calving group. Cows were fed a total mixed ration (TMR), with minor adaptations of the ration according to the group.

The beef cows studied $(n=5,700)$ belonged to the Limousine and Romagnola breeds, reared according to the cowcalf line, with grazing animals and minimal feed supplements.

Uterine prolapse was defined as protrusion of the uterus from the vulva following parturition. Veterinary intervention by experienced cattle practitioners was ensured within $1 \mathrm{~h}$ after request from the farmer, and the technique of prolapse reduction was adjusted after a case-by-case evaluation of the cow's clinical condition. For cows in standing position, restraint was obtained in caudal epidural anaesthesia with Lidocaine $\mathrm{HCl} 2 \%^{\circledR}$ (Fort Dodge Animal Health S.p.A., Overland Park, Kansas, USA) and with i.m. xylazine ( $5 \mathrm{mg} / 100$ $\mathrm{kg}$, Rompun ${ }^{\circledR}$ Bayer S.p.A., Garbagnate Milanese, Italy). For some Limousine cows, a higher dose of xylazine $(20 \mathrm{mg} / 100$ $\mathrm{kg}$ ) was necessary for restraint. Replacing the uterus in cows in recumbent position was performed by positioning the cow in sternal recumbency with both hind legs extended out behind, with the head facing downhill ('Okie position') (Peter, 2015). This position tilts the pelvis forward and avoids straining, thus facilitating uterine replacement (Richter and Goetze, 1986; Peter, 2015). A urinary catheter was placed in cases of concurrent bladder eversion, to facilitate emptying and replacement. The prolapsed mass was rinsed thoroughly with cold saline solution and chlorhexidine, and it was lubricated with sterile vaseline, followed by massaging and replacing it carefully after holding it up with gloved hands and pushing it into the cow's pelvis (Bhattacharyya et al., 2012). Downer cows with clinical signs of hypocalcaemia were treated with $200-250 \mathrm{~mL} /$ cow of calcium borogluconate (Glucalene CEVA Vetem ${ }^{\circledR}$, Italy) administered intravenously. After uterine replacement, all cows received a single intrauterine dose of $200 \mathrm{mg}$ rifaximin (Fatroximin Schiuma ${ }^{\mathbb{R}}$, Fatro Industria Farmaceutica Veterinaria, Ozzano dell'Emilia, BO, Italy). At the end of the intervention, a harness of ropes was applied on both sides of the vulva as a means of containment of the uterus.

The cows were then monitored in order to evaluate the outcome of the intervention and the presence of complications, and to assess their subsequent fertility. Starting from 50 days after calving (voluntary waiting period), the recovered dairy cows in oestrus (pre-ovulatory follicle, normal genital tract conditions detected by transrectal palpation) were submitted to artificial insemination (AI) with semen of proven fertility, while beef cows were naturally mated with a bull of proven fertility; therefore the exact period of fertilisation could not be precisely assessed for beef cows. For dairy cows, pregnancy diagnosis was performed by veterinarians through rectal palpation at $40-45$ days after AI; for a positive diagnosis, confirmation was performed at 90 days after AI. Regarding beef cows, pregnancy diagnosis was performed by the veterinarian during the monthly herd health visits.

Data regarding the prevalence of prolapse, attitude and parity (primiparous versus multiparous) of affected cows, survival, subsequent fertility and possible recurrence of the prolapse at the subsequent parturition were recorded. Data on culling included cows that recovered from prolapse but were voluntarily culled by the farmer because of low production, low fertility or unsatisfactory recovery of the nutritional status. Mortality rates referred to cows that died before treatment plus cows that did not recover after treatment. When calculating fertility, the conception rate was defined as the percentage of pregnant cows/inseminated cows. According to the guidelines of our Institutions, a formal approval from the Ethics Committee was not required since the replacement of the prolapsed uterus was performed for routine therapy purposes. 


\section{RESULTS}

There were 216 cases of uterine prolapse out of a total of 33,450 calvings $(0.6 \%)$. The prevalence of uterine prolapse according to purpose of utilisation and parity of the cows, the voluntary culling rate, the mortality rate, and the conception rate are presented in Table 1 . Of the 18 deaths, 7 (38.8\%) occurred on the same day as the prolapse (2 deaths before the attempt of replacement and 5 after replacement of the uterus), while 11 (61.1\%) occurred within $24 \mathrm{~h}$ after calving. Replacement of the prolapsed uterus was performed in recumbent position except in the case of 16 dairy cows (7.4\% of all prolapses) in which it was done in standing position. Hypocalcaemia was detected and treated in 9 out of the 216 cases of prolapse (4.2\% of prolapses). Regarding fertility in dairy cows, 21 of the 129 cows (19.4\%) became pregnant at the first insemination, $38(35.2 \%)$ at the second service, $25(23.1 \%)$ at the third service, and $12(11.1 \%)$ at the fourth and fifth services each. Due to the use of natural mating, the exact period of fertilisation (and, consequently, the calving to conception interval) could not be precisely determined for beef cows; however, 42 out of 48 cows (87.5\%) were assessed to be pregnant within three months after the replacement of the prolapsed uterus. Among the 216 uterine prolapses, there was only one case of recurrence at the subsequent calving in an Italian Friesian cow.

\section{DISCUSSION}

Uterine prolapse in the cow is regarded as an emergency but sporadic event associated with calving (Miesner and Anderson, 2008). The prevalence of $0.6 \%$, found in the total bovine population in our study, largely corresponded to previous

Table 1. Data (number and \%) regarding prevalence and distribution of uterine prolapse, mortality rate, culling rate, survival, and fertility of the affected cows

\begin{tabular}{lccc}
\hline & $\begin{array}{c}\text { Dairy cows } \\
\mathrm{n}=27,750\end{array}$ & $\begin{array}{c}\text { Beef cows } \\
\mathrm{n}=5,700\end{array}$ & $\begin{array}{c}\text { Total } \\
\mathrm{n}=33,450\end{array}$ \\
\hline $\begin{array}{c}\text { Uterine prolapse, } \\
\mathbf{n} \text { (\%) }\end{array}$ & $159(0.6 \%)$ & $57(1 \%)$ & $216(0.6 \%)$ \\
primiparous & $26(16.4 \%)$ & $7(12.3 \%)$ & $33(15.3 \%)$ \\
$\quad$ multiparous & $133(83.6 \%)$ & $50(87.7 \%)$ & $183(84.7 \%)$ \\
Mortality, n (\%) & $12(5.5 \%)$ & $6(2.8 \%)$ & $18(8.3 \%)$ \\
Culling, n (\%) & $18(8.3 \%)$ & $3(1.4 \%)$ & $21(9.7 \%)$ \\
Survived, n (\%) & $129(81.1 \%)$ & $48(84.4 \%)$ & $177(81.9 \%)$ \\
Inseminated, n & 129 & 48 & 177 \\
Conceived, n & 108 & 42 & 150 \\
Conception & $83.7 \%$ & $87.5 \%$ & $84.7 \%$ \\
$\quad$ rate (\%) & & & - \\
Calving to & 101.5 & $\mathrm{na}$ & - \\
$\quad$ conception & & & \\
$\quad$ interval (days) & & & $\mathrm{na}$ \\
Primiparous & 97.7 & $\mathrm{na}$ & - \\
Multiparous & 105.3 & & \\
\hline
\end{tabular}

na: not applicable estimates (Richter and Goetze, 1986; Noakes et al., 2001). The higher prevalence in multiparous cows reported in the literature was confirmed by the present data, both in dairy and beef breeds, although some authors (Murphy and Dobson, 2002) observed a predisposition in younger beef animals compared to multiparous ones. Contrary to what was reported by many authors (Vandeplassche et al., 1963; Noakes et al., 2001; Miesner and Anderson, 2008), in this study the prevalence of uterine prolapse was found to be higher in beef than in dairy cows $(1 \%$ vs. $0.6 \%)$. Moreover, the prevalence found in beef cows in the present study was three times higher than that reported in other beef cattle breeds $(0.2-0.3 \%)$ (Woodward and Quesenberry, 1956; Patterson et al., 1981). A study recently performed on the same Italian beef breed (Romagnola) (De Amicis et al., 2018) found that uterine atony was the main cause of dystocia of maternal origin in multiparous beef cows. Reduced uterine contractility, resulting in uterine atony, is reported as a main cause of uterine prolapse, and it can therefore be responsible for the high prevalence of prolapse detected among beef cows in the present study.

In this study, the survival rate of cows treated for uterine prolapse $(91.7 \%)$ was higher than in other studies on dairy cattle (73.5\%, Jubb et al., 1990; 80\%, Murphy and Dobson, 2002), but similar to that reported by Bhattacharyya et al. (2012) (90.9\%). When data on voluntary culling are also considered, the total losses caused by uterine prolapse (18\%) are similar to those reported in other studies. Prognosis for life is thought to be positive with timely intervention (Miesner and Anderson, 2008), and veterinary intervention in the present study was ensured within $1 \mathrm{~h}$ after call, minimising animal discomfort and tissue damage. This may explain the low mortality rate recorded in the present study. Moreover, Odegaard (1977) reported a high mortality rate in prolapse cases associated with hypocalcaemia; the prevalence of concurrent hypocalcaemia in cows with uterine prolapse in the present study was $4.2 \%$, much lower than the $19 \%$ found by Risco et al. (1984) in dairy cows, much lower than the $44 \%$ detected by Murphy and Dobson (2002) in dairy and beef cows, and much lower than the $42.3 \%$ assessed by Richardson et al. (1981) in beef cattle. The definition of hypocalcaemia may vary among studies, making comparisons unreliable, but these data confirm the importance of recognition and adequate treatment of concurrent disorders in the event of uterine prolapse. Delivering a live calf can improve the survival rate of cows with uterine prolapse (Potter, 2008), but unfortunately such data were not available in the present study.

Regarding the type of resolution, the adoption of the Okie position minimises physical effort and offers considerable advantages, since the expulsive forces are abundantly suppressed, and the pelvic floor represents a useful support for repositioning the uterus. Finally, the position adopted by the prolapsed organ allows a good reactivation of circulation, otherwise compromised by vascular constriction at the level of the ischial arch, and worsened by the weight of the dislocated uterus. No Buhner's stitch or other suture techniques were applied in the present study, but the uterus was held in place by a harness of ropes applied on both sides of the vulva. The fact that no recurrence of uterine prolapse 
was recorded in the short time period seems to support the unnecessity of specific vaginal retention sutures.

In cows, endometrial repair starts immediately after parturition, and epithelial regeneration in severely damaged areas such as the caruncles is complete in as few as 25 days (Dobson-Hill, 2009; Lara et al., 2017). The degree of trauma to the uterus and the time it takes to repair have a significant effect on fertility (Odegaard, 1977). Therefore, as a consequence of uterine prolapse, and also of some predisposing factors such as dystocia and hypocalcaemia, an extended calving-to-conception interval can be detected (Borsberry and Dobson, 1989), since all these events may cause a delay in uterine involution. In the present study, the evaluation of long-term effects on fertility showed satisfactory results among recovered cows. The total conception rate was in accordance with data from previous studies (Odegaard, 1977; Jubb et al., 1990; Miesner and Anderson, 2008; Ishii et al., 2010); data concerning dairy cows, for which precise information on the timing of AI was available, showed that $77 \%$ of cows conceived within the third service (within 4 months after calving), and this result can be regarded as satisfactory if compared with the optimal fertility, i.e. a $90 \%$ pregnancy rate to be obtained after three services in healthy cows (Peter, 2015). The calving-to-conception interval was shorter than that recorded by Odegaard (1977), especially when referred to primiparous cows only.

For beef cows, these additional data on the calving-toconception interval were not available, due to the use of natural breeding; however, it was possible to detect a satisfactory conception rate within three months after resolution of the disease. These consistent and satisfactory findings between investigations on uterine prolapse indicate the remarkable healing ability of the bovine uterus also after prolapse. Comparing the present data with those reported previously, it is clear that the correct and timely treatment of uterine prolapse is of fundamental importance for the functional recovery of the uterus and for fertility.

In conclusion, on the basis of the data presented here, cows with uterine prolapse have almost no risk of recurrence as well as good chances of survival and conception if the prolapse is treated early and in a correct manner.

\section{REFERENCES}

Bhattacharyya, H. K., Fazili, M. R., Buchoo, B. A. and Akand, A. H. (2012): Genital prolapse in crossbred cows: prevalence, clinical picture and management by a modified Buhner's technique using infusion (drip) set tubing as suture material. Vet. Arh. 82, 11-24.

Borsberry, S. and Dobson, H. (1989): Periparturient diseases and their effect on reproductive performance in five dairy herds. Vet. Rec. 124, 217-219.

De Amicis, I., Veronesi, M. C., Robbe, D., Gloria, A. and Carluccio, A. (2018): Prevalence, causes, resolution and consequences of bovine dystocia in Italy. Theriogenology. 107, 104-108.
Dobson-Hill, B. (2009): Uterine Involution in the Dairy Cow: Comparative Study Between Organic and Conventional Dairy Cows, Master's Thesis, Massey University, Palmerston North, New Zealand.

Gardner, I. A., Reynolds, J. P., Risco, C. A. and Hird, D. W. (1990): Patterns of uterine prolapse in dairy cows and prognosis after treatment. J. Am. Vet. Med. Assoc. 197, 1021-1024.

Ishii, M., Aoki, T., Yamakawa, K., Uyama, T., El-khodery, S., Matsui, M. and Miyake, Y. (2010): Uterine prolapse in cows: effect of raising the rear end on the clinical outcomes and reproductive performance. Vet. Med-Czech 55, 113-118.

Jubb, T. F., Malmo, J. and Brightling, P. (1990): Survival and fertility after uterine prolapse in dairy cows. Aust. Vet. J. 67, $22-24$.

Lara, E., Velásquez, A., Cabezas, J., Rivera, N., Pacha, P., RodríguezAlvarez, L., Saravia, F. and Castro, F. O. (2017): Endometritis and in vitro $\mathrm{PGE}_{2}$ challenge modify properties of cattle endometrial mesenchymal stem cells and their transcriptomic profile. Stem Cell. Int. 2017, 4297639.

Miesner, M. D. and Anderson, D. E. (2008): Management of uterine and vaginal prolapse in the bovine. Vet. Clin. Food Anim. 24, 409-419.

Murphy, A. M. and Dobson, H. (2002): Predisposition, subsequent fertility, and mortality of cows with uterine prolapse. Vet. Rec. 151, 733-735. 12509078.

Noakes, E. D. (1986): Fertility and Obstetrics in Cattle, Blackwell Scientific Publications, Oxford. pp. 96-99.

Noakes, E. D., Parkinson, T. J. and England, G. C. W. (2001): Postparturient prolapse of the uterus. In: Arthur's Veterinary Reproduction and Obstetrics. 8th edition, Harcourt (India) Pvt. Ltd., New Delhi. pp. 333-338.

Peter, A. (2015): Vaginal, cervical and uterine prolapse. In: Hopper, R. M. (ed) Bovine Reproduction, Wiley and Sons Inc. pp. 384-395.

Odegaard, S. A. (1977): Uterine prolapse in dairy cows. Acta Vet. Scand. Suppl. 63, 1-124. 271460.

Patterson, D. J., Bellowska, R. A. and Burfening, P. J. (1981): Effects of caesarean section, retained placenta and vaginal or uterine prolapse on subsequent fertility in beef cattle. J. Anim. Sci. 53, 916-921.

Potter, T. (2008): Prolapse of the uterus in the cow. UK Vet. 13, 1-4.

Richardson, G. F., Klemmer, A. D. and Knudsen, D. B. (1981): Observations in uterine prolapse in beef cattle. Can. Vet. J. 22, 189-191. 7284951.

Richter, J. and Goetze, R. (1986): Inversion and prolapse of the uterus [in Italian]. In: Ostetricia Veterinaria, Editoriale Grasso. pp. $425-436$.

Risco, C. A., Reynolds, J. P. and Hird, D. (1984): Uterine prolapse and hypocalcemia in dairy cows. J. Am. Vet. Med. Assoc. 185, 1517-1519. 6511623.

Roberts, S. J. (1986): Veterinary Obstetrics and Genital Diseases (Theriogenology), 3rd edition, North Pomfret, Vt.

Vandeplassche, M., Paredis, F., Bouters, R. and Spincemaille, J. (1963): Caesarean Section for Emphysematous Fetuses, Die Blauen Hefte Für Den Tierarzt. 1963.

Woodward, R. R. and Quesenberry, A. A. , Jr. (1956): Study of vaginal and uterine prolapse in Hereford cattle. J. Anim. Sci. 15, 119-124. 